\title{
Time Series Analysis and Data Relationships
}

\author{
Y. Bicen, M. Kayikci, and F. Aras
}

\begin{abstract}
The time-series models which has an has an important place in the statistical forecasting methods are widely used in many disciplines such as economy, production management, and engineering in order to perform realistic estimates for the future. Produced results of these methods which are diversified in time, is variable for different data sets. A model that produces pretty good results for a dataset may not be realistic for the other dataset. The success of the time-series forecasting methods is directly related to the quantitative characteristic features of a dataset ranked through time. In this study, it is tried to identify the main principles for determining the correct method and suitably selecting the parameters within the framework of time-series forecasting models and quantitative characteristics of the data sets.
\end{abstract}

Index Terms - Exponential smoothing, forecasting methods, time series, statistics.

\section{INTRODUCTION}

$\mathrm{T}$ ODAY, forward-looking strategic planning is needed for a competitive free market economy. In this sense, monitoring of the balance between demands and manufactured products continually is critical to make accurate assessments. Time series methods which are classified in quantitative forecasting methods are used effectively quite a long time in particular to estimate short and medium-term data. Time-series forecasting models utilize historical data lined up at regular intervals. It is possible to encounter many different varieties such as simple moving averages, exponential smoothing methods, adaptive smoothing methods, and etc. Certainly, the reason for the emergence of many types of methods is due to the changing of success level according to different data characteristics. In this study, some of time-series forecasting models and the relationships among their performances with the series characteristics are examined.

Y. BICEN is with the DMYO, the Department of Electronics and Automation, Duzce University, Uzunmustafa, 81010, Duzce, Turkey. (e-mail: yunusbicen@duzce.edu.tr)

M. KAYIKCI is with the DMYO, the Department of Computer Technologies, Duzce University, Uzunmustafa, 81010, Duzce, Turkey. (e-mail: mustafakayikci@duzce.edu.tr).

F. ARAS is with the Department of Aircraft Electrical and Electronics, Kocaeli University, Turkey (e-mail: faruk.aras@kocaeli.edu.tr).

\section{THE TIME SERIES ANALYSIS}

The preferred time series models are differ from each other according to the data sets in various sectors. In the literature, the time series characteristics are described in principle generally [1-4]. The characteristics changes shown in Fig. 1 may be involved individually or in combination in the time series. In such a case, the method to be used should be selected correctly in order to make accurate forecasts or time series analysis.

\section{Trend:}

It refers to the long term upward or downward changes. Linear, exponential or logarithmic may be.

\section{Seasonal changes:}

It refers to short-term and regular changes within a certain period.

\section{Conjectural changes:}

It refers to long-term and cyclical changes.

\section{Deviations:}

It refers to non-periodic unusual changes.

\section{Random changes:}

It refers to all changes except the other changes.

From simple to complex, there are many time-series analysis methods. One of the most successful methods following the characteristic of time series is exponential smoothing method [5]. Brown and Holt's (1950) exponential smoothing method has been developed and many additions have been made on original method during this time [1,5-7]. In the literature first time, exponential smoothing method has been classified by Pegels (1969) for different combinations of trends and seasonal changes. And then, this classification has been extended by Gardner, McKenzie and Taylor [2,8]. As is apparent from Table 1 , trend and seasonal components are not a function of each other in additive model but these components varies in direct proportion to each other in the multiplicative model.

Three different parameters $\alpha, \beta$, and $\delta$ used in the Extended exponential smoothing method, refer to the level, the trend, and the seasonal components respectively. 
TABLE I

EXTENDED EXPONENTIAL SMOOTHING STATEMENTS

\begin{tabular}{|c|c|c|c|c|}
\hline & \multicolumn{3}{|c|}{ Seasonality } \\
\hline & & None & Additive & Multiplicative \\
\hline \multirow{5}{*}{ 항 } & None & $\begin{array}{l}S_{t}=\alpha X_{t}+(1-\alpha) S_{t-1} \\
\hat{X}_{t}(m)=S_{t}\end{array}$ & $\begin{array}{l}S_{t}=\alpha\left(X_{t}-I_{t-p}\right)+(1-\alpha) S_{t-1} \\
I_{t}=\delta\left(X_{t}-S_{t}\right)+(1-\delta) I_{t-p} \\
\hat{X}_{t}(m)=S_{t}+I_{t-p+m}\end{array}$ & $\begin{array}{l}S_{t}=\alpha\left(X_{t} / I_{t-p}\right)+(1-\alpha) S_{t-1} \\
I_{t}=\delta\left(X_{t} / S_{t}\right)+(1-\delta) I_{t-p} \\
\hat{X}_{t}(m)=S_{t} I_{t-p+m}\end{array}$ \\
\hline & Additive & $\begin{array}{l}S_{t}=\alpha X_{t}+(1-\alpha)\left(S_{t-1}+T_{t-1}\right) \\
T_{t}=\beta\left(S_{t}-S_{t-1}\right)+(1-\beta) T_{t-1} \\
\hat{X}_{t}(m)=S_{t}+m T_{t}\end{array}$ & $\begin{array}{l}S_{t}=\alpha\left(X_{t}-I_{t-p}\right)+(1-\alpha)\left(S_{t-1}+T_{t-1}\right) \\
T_{t}=\beta\left(S_{t}-S_{t-1}\right)+(1-\beta) T_{t-1} \\
I_{t}=\delta\left(X_{t}-S_{t}\right)+(1-\delta) I_{t-p} \\
\hat{X}_{t}(m)=S_{t}+m T_{t}+I_{t-p+m}\end{array}$ & $\begin{array}{l}S_{t}=\alpha\left(X_{t} / I_{t-p}\right)+(1-\alpha)\left(S_{t-1}+T_{t-1}\right) \\
T_{t}=\beta\left(S_{t}-S_{t-1}\right)+(1-\beta) T_{t-1} \\
I_{t}=\delta\left(X_{t} / S_{t}\right)+(1-\delta) I_{t-p} \\
\hat{X}_{t}(m)=\left(S_{t}+m T_{t}\right) I_{t-p+m}\end{array}$ \\
\hline & Multiplicative & $\begin{array}{l}S_{t}=\alpha X_{t}+(1-\alpha)\left(S_{t-1} R_{t-1}\right) \\
R_{t}=\beta\left(S_{t} / S_{t-1}\right)+(1-\beta) R_{t-1} \\
\hat{X}_{t}(m)=S_{t} R_{t}^{m}\end{array}$ & $\begin{array}{l}S_{t}=\alpha\left(X_{t}-I_{t-p}\right)+(1-\alpha)\left(S_{t-1} R_{t-1}\right) \\
R_{t}=\beta\left(S_{t} / S_{t-1}\right)+(1-\beta) R_{t-1} \\
I_{t}=\delta\left(X_{t}-S_{t}\right)+(1-\delta) I_{t-p} \\
\hat{X}_{t}(m)=S_{t} R_{t}^{m}+I_{t-p+m}\end{array}$ & $\begin{array}{l}S_{t}=\alpha\left(X_{t} / I_{t-p}\right)+(1-\alpha)\left(S_{t-1} R_{t-1}\right) \\
R_{t}=\beta\left(S_{t} / S_{t-1}\right)+(1-\beta) R_{t-1} \\
I_{t}=\delta\left(X_{t} / S_{t}\right)+(1-\delta) I_{t-p} \\
\hat{X}_{t}(m)=\left(S_{t} R_{t}^{m}\right) I_{t-p+m}\end{array}$ \\
\hline & $\begin{array}{l}\text { Additive } \\
\text { damped }\end{array}$ & $\left\{\begin{array}{l}S_{t} \\
=\alpha X_{t}+(1-\alpha)\left(S_{t-1}+\emptyset T_{t-1}\right) \\
T_{t} \\
=\beta\left(S_{t}-S_{t-1}\right)+(1-\beta) \emptyset T_{t-1} \\
\hat{X}_{t}(m)=S_{t}+\sum_{i=1}^{m} \emptyset^{i} T_{t}\end{array}\right.$ & $\left\{\begin{array}{l}S_{t}=\alpha\left(X_{t}-I_{t-p}\right)+(1-\alpha)\left(S_{t-1}+\emptyset T_{t-1}\right) \\
T_{t}=\beta\left(S_{t}-S_{t-1}\right)+(1-\beta) \emptyset T_{t-1} \\
I_{t}=\delta\left(X_{t}-S_{t}\right)+(1-\delta) I_{t-p} \\
\hat{X}_{t}(m)=S_{t}+\sum_{i=1}^{m} \phi^{i} T_{t}+I_{t-p+m}\end{array}\right.$ & $\begin{array}{r}S_{t}=\alpha\left(X_{t} / I_{t-p}\right)+(1-\alpha)\left(S_{t-1}\right. \\
\left.\quad+\emptyset T_{t-1}\right) \\
T_{t}=\beta\left(S_{t}-S_{t-1}\right)+(1-\beta) \emptyset T_{t-1} \\
I_{t}=\delta\left(X_{t} / S_{t}\right)+(1-\delta) I_{t-p}\end{array}$ \\
\hline & $\begin{array}{l}\text { Multiplicative } \\
\text { damped }\end{array}$ & $\begin{array}{l}S_{t}=\alpha X_{t}+(1-\alpha)\left(S_{t-1} R_{t-1}^{\emptyset}\right) \\
R_{t}=\beta\left(S_{t} / S_{t-1}\right)+(1-\beta) R_{t-1}^{\emptyset} \\
\hat{X}_{t}(m)=S_{t} R_{t}^{\sum_{i=1}^{m} \phi^{i}}\end{array}$ & $\begin{array}{l}S_{t}=\alpha\left(X_{t}-I_{t-p}\right)+(1-\alpha)\left(S_{t-1} R_{t-1}^{\emptyset}\right) \\
R_{t}=\beta\left(S_{t} / S_{t-1}\right)+(1-\beta) R_{t-1}^{\emptyset} \\
I_{t}=\delta\left(X_{t}-S_{t}\right)+(1-\delta) I_{t-p} \\
\hat{X}_{t}(m)=S_{t} R_{t}^{\sum_{i=1}^{m} \phi^{i}}+I_{t-p+m}\end{array}$ & $\begin{array}{l}S_{t}=\alpha\left(X_{t} / I_{t-p}\right)+(1-\alpha)\left(S_{t-1} R_{t-1}^{\emptyset}\right) \\
R_{t}=\beta\left(S_{t} / S_{t-1}\right)+(1-\beta) R_{t-1}^{\emptyset} \\
I_{t}=\delta\left(X_{t} / S_{t}\right)+(1-\delta) I_{t-p} \\
\hat{X}_{t}(m)=\left(S_{t} R_{t}^{\sum_{i=1}^{m} \phi^{i}}\right) I_{t-p+m}\end{array}$ \\
\hline \multicolumn{2}{|c|}{$\alpha$} & \multicolumn{3}{|c|}{ Smoothing parameter for the level of the series } \\
\hline \multicolumn{2}{|c|}{ B } & \multicolumn{3}{|c|}{ Smoothing parameter for the trend } \\
\hline \multicolumn{2}{|c|}{$\delta$} & \multicolumn{3}{|c|}{ Smoothing parameter for seasonal indices } \\
\hline \multicolumn{2}{|c|}{$\phi$} & \multicolumn{3}{|c|}{ Damping parameter } \\
\hline \multicolumn{2}{|c|}{$m$} & \multicolumn{3}{|l|}{ Number forecast period } \\
\hline \multicolumn{2}{|c|}{$p$} & \multicolumn{3}{|c|}{ Number of periods in the seasonal cycle } \\
\hline \multicolumn{2}{|l|}{$S_{t}$} & \multicolumn{3}{|c|}{ Smoothed level of the series in period(t) } \\
\hline \multicolumn{2}{|l|}{$X_{t}$} & \multicolumn{3}{|c|}{ Observed value of the time series in period(t) } \\
\hline \multicolumn{2}{|c|}{$\hat{X}_{t}(m)$} & \multicolumn{3}{|c|}{ Forecast for $m$ periods ahead from ( $t$ ) } \\
\hline \multicolumn{2}{|c|}{$T_{t}$} & \multicolumn{3}{|c|}{ Smoothed additive trend in period(t) } \\
\hline \multicolumn{2}{|c|}{$R_{t}$} & \multicolumn{3}{|c|}{ Smoothed multiplicative trend in period(t) } \\
\hline \multicolumn{2}{|l|}{$I_{t}$} & \multicolumn{3}{|c|}{ Smoothed seasonal index in period(t) } \\
\hline
\end{tabular}



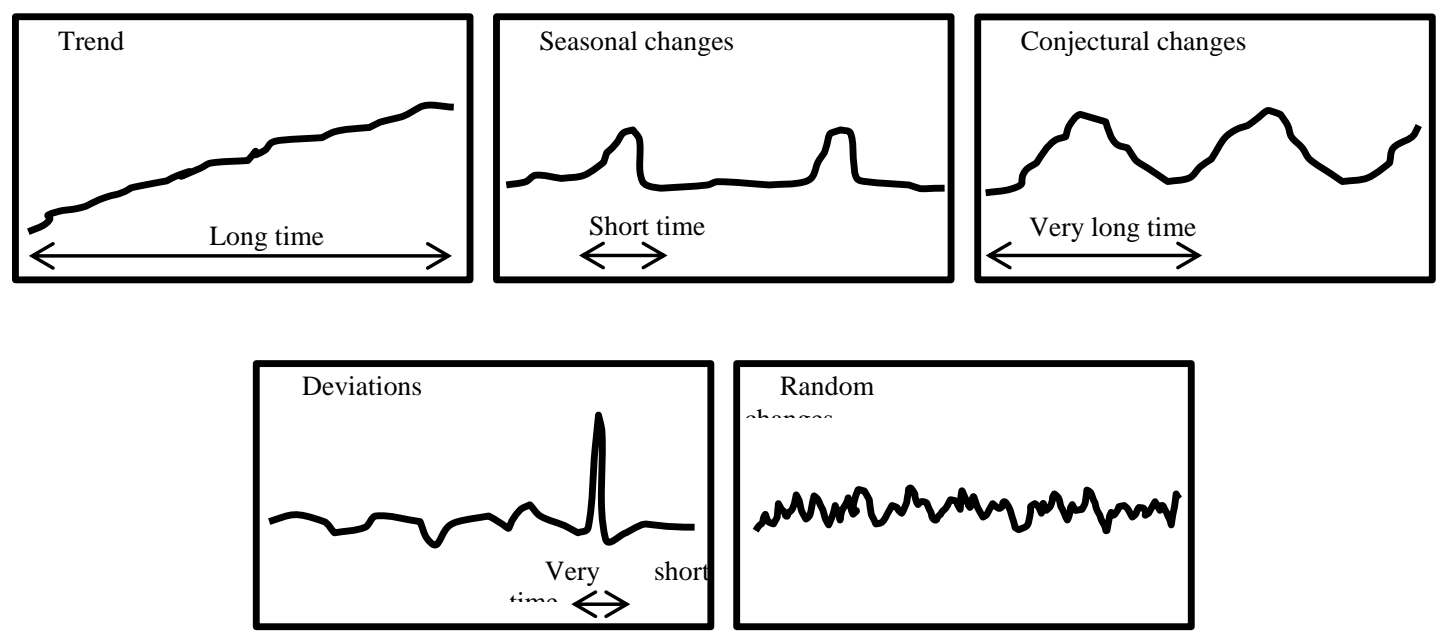

Fig. 1. The characteristics of the time series

Each one is selected independently according to the characteristics of the time series. Except for some studies, these parameters are chosen between 0 and +1 value as a general rule. Selecting of each parameter close to the value 0 , it means reduced sensitivity to noise on the related components. But in this case, it becomes difficult to catch the changes of the related components. If the parameters are selected close to the value +1 , the changes of the related components may be quickly caught. But in this case, noise will be effective on the estimates. If there are non-uniform or step changes of the time series, the error rates increase. Therefore, a different approach emerged that the smoothing factor should be changed sensitive to current changes of the time series. There are many methods introduced within the scope adaptive smoothing title but the most wellknown method is Trigg and Leach version in the literature [5, 9]. This method is based on simple exponential smoothing method and only $\alpha$ parameter is adjusted.

$$
\begin{aligned}
& S_{t+1}=\alpha_{t} X_{t}+\left(1-\alpha_{t}\right) S_{t} \\
& a_{t}=\left|\frac{E_{t}}{A_{t}}\right| \\
& E_{t}=\gamma e_{t}+(1-\gamma) E_{t-1} \\
& A_{t}=\gamma\left|e_{t}\right|+(1-\gamma) A_{t-1}
\end{aligned}
$$

Where, $\alpha_{t}$ refers to the smoothing factor in period $(t), E_{t}$ refers to the smoothed forecast error, At refers to the smoothed absolute error, $\gamma$ refers to the arbitrarily selected constant, and et refers to the forecast error $\left(e_{t}=X_{t}-S_{t}\right)$ in period $(t)$. Although the Trigg and Leach method is one of the pioneer studies in adaptive smoothing methods, some cases it produces unstable forecast results [1,5]. Moreover, there are many studies used fixed smoothing factor that give better results than the adaptive version $[1,10,11]$. Regarding the adaptive smoothing approach, newly and promising studies continue for different time series characteristics [5, 12-17].

\section{QUANTITATIVE ANALYSIS}

Simple Exponential smoothing (SES) and weighted moving average (WMA) methods are very similar mathematically. In both methods, it is important to choose right parameters according to the data set in order to reduce error rates. As shown in Fig. 2, the parameters are chosen $(n=3 ; 0.5,0.3,0.2)$ for WMA method and $(\alpha=0.8)$ for ES method. ES method has two advantages compared to WMA method. The first, the forecast could start from the second iteration and secondly, the equation is simpler.

The objective function that minimizes the mean squared error can be used for the selection of the optimal smoothing factor. The changes of the time series are shown in Fig. 3 for large, small, and optimal values of the smoothing parameters. Mean square errors are found 1164 for $\alpha=0.8,1118$ for $\alpha=0.55$, and 1215 for $\alpha=0.2$, respectively. Optimal value of $\alpha$ contained herein is calculated considering the whole time series. Therefore, using optimal factor will not be eligible for the next estimates, if there are the major changes that have occurred in the recent period of the series. In such cases, adaptive smoothing method is advisable.

The extended models of exponential smoothing, trends and seasonality components can be incorporated into the series; it enables to make more accurate estimates. Trends and seasonality components in the expanded exponential smoothing methodology presented in Table 1 can be analyzed as additive or multiplicative in the series. However, the choice of multiplicative model gives better results for the time series which includes linear and nonlinear trend. This situation may be understood from time series analysis in Fig. 4 and the rate of errors in Table 2. The time series including trend and seasonality, in the process of determination of the factors $\alpha, \beta$ and $\delta$, it can be monitored which component is more effective 
on the series. Here, the objective function that minimizes the determining the appropriate factors. mean squared error mentioned above can be used in

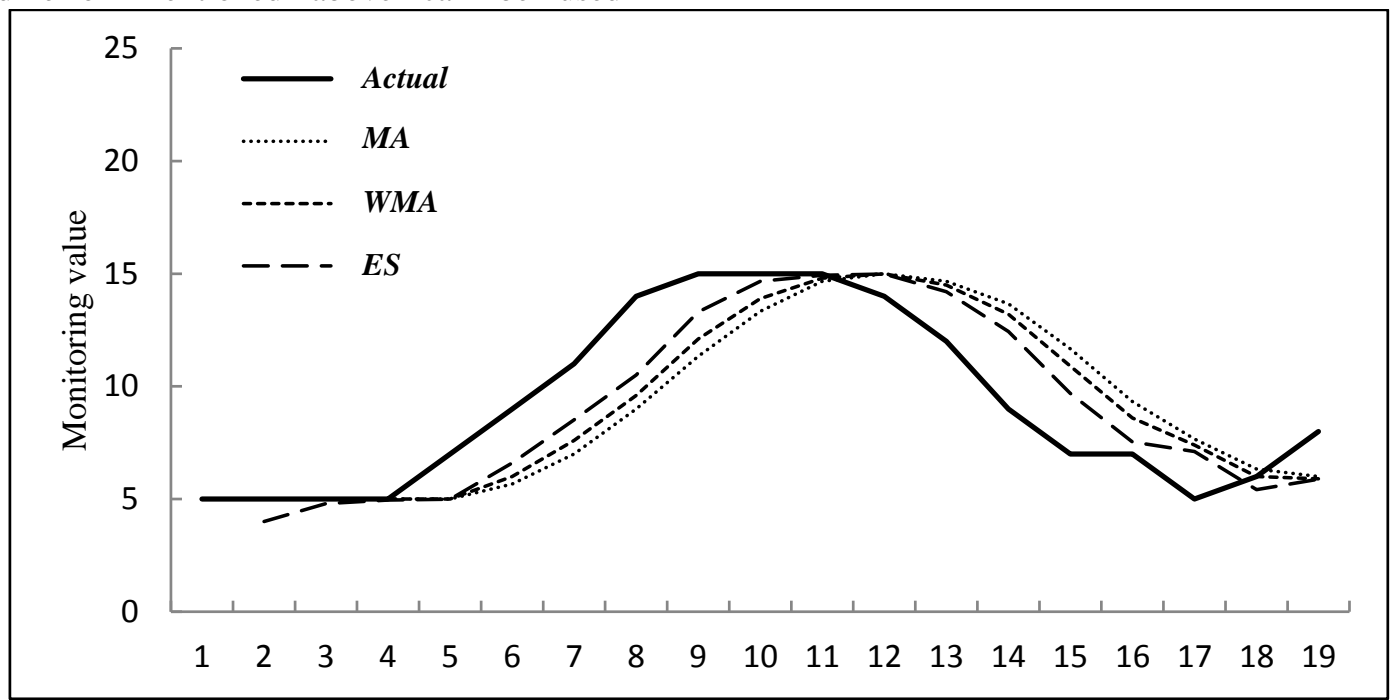

Fig. 2. The comparative forecast changes

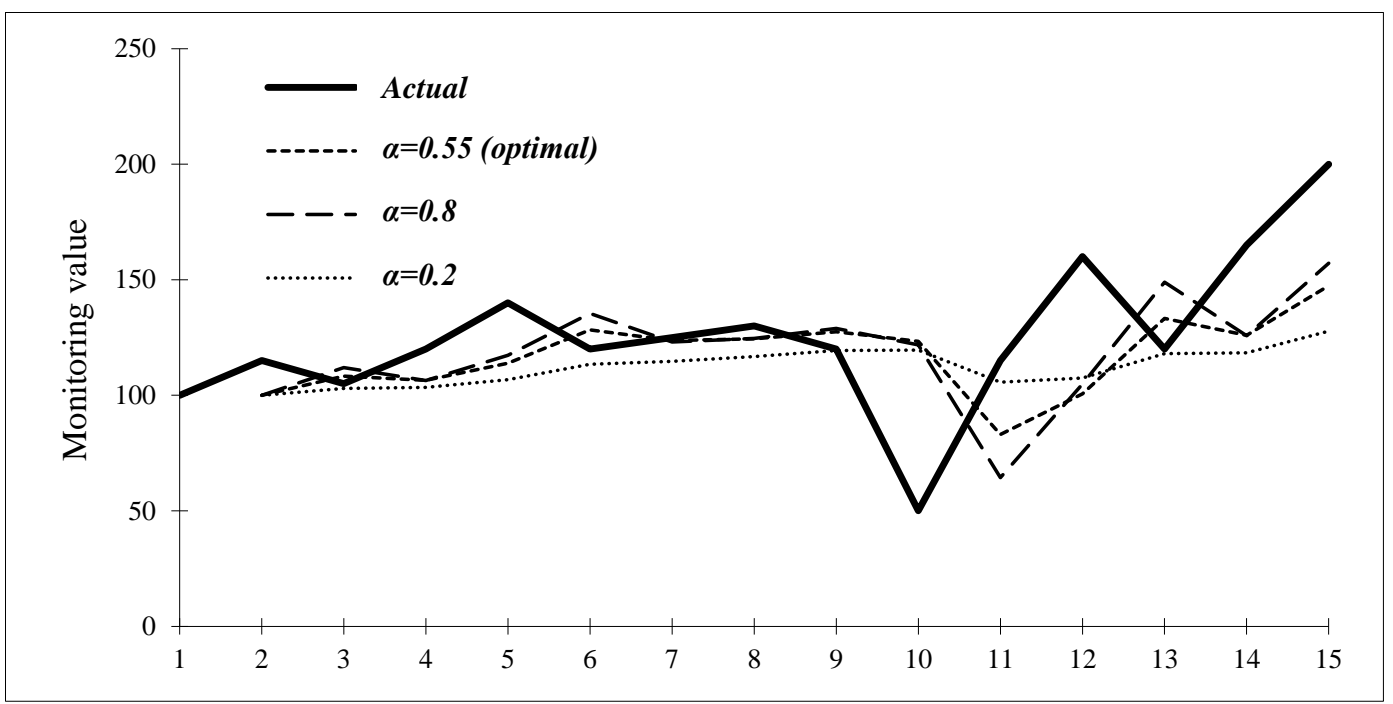

Fig. 3. The forecast changes for different $\alpha$ factors

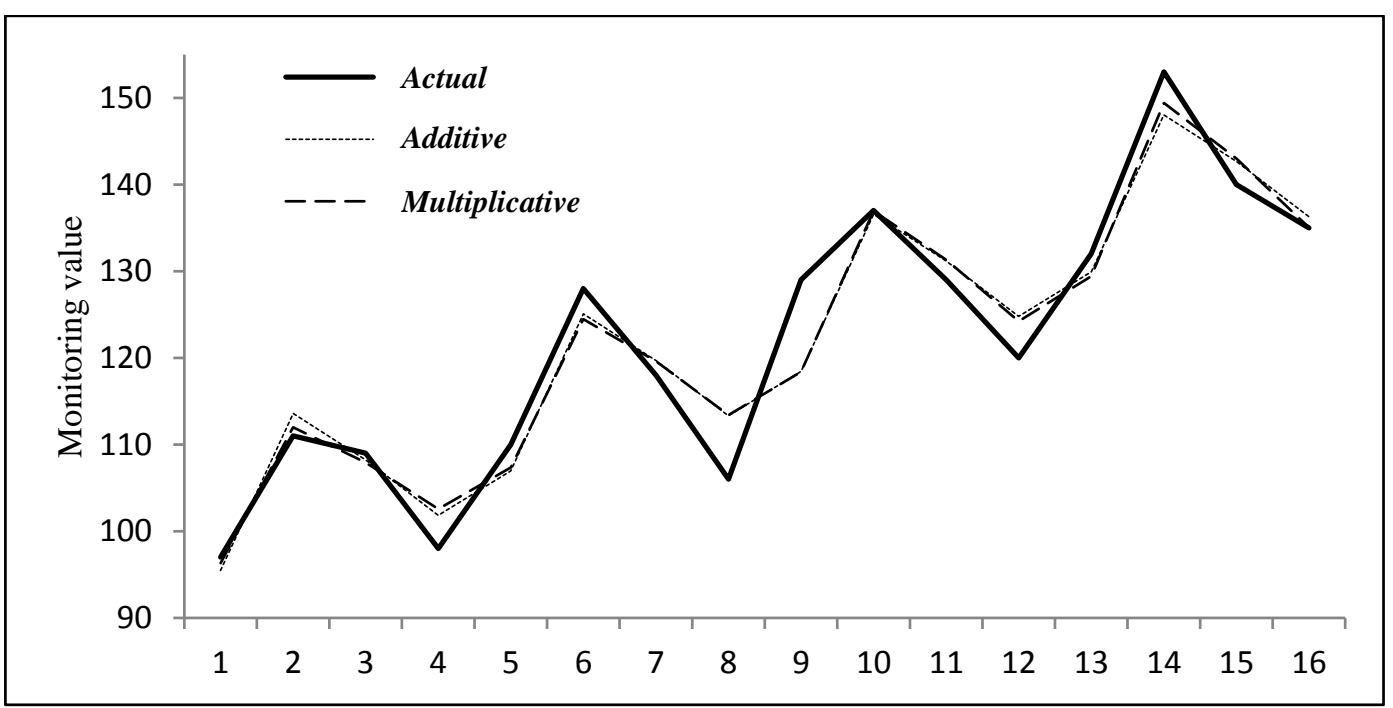

Fig. 4. The forecast changes for extended exponential smoothing methods 
TABLE 2

STATistical EVALUATION (FOR FigURe 4)

\begin{tabular}{lccc}
\hline \hline \multirow{2}{*}{ Method } & \multicolumn{3}{c}{ Errors } \\
\cline { 2 - 4 } & MAD & MSE & MAPE \\
\cline { 2 - 4 } Multiplicative (ES) & 3.06 & 16.57 & $2.55 \%$ \\
Additive (ES) & 3.29 & 17.24 & $2.74 \%$ \\
\hline \hline
\end{tabular}

\section{RESULTS AND DiSCUSSION}

The characteristic of time series has a major importance to determine the methods and to select the smoothing factors used in the related method. Some suggestions should be considered in the choice of the factors for simple or expanded exponential smoothing methods:

\section{For simple exponential smoothing;}

- If the time series are unidirectional and stable, $\alpha$ can be selected close to 1 ,

- If the series changes character and continuous as the longterm stable, $\alpha$ can be selected close to 1 ,

- If there are short-term and continuing fluctuations in series, $\alpha$ can be selected close to 0 ,

\section{For extended exponential smoothing;}

- If the series contains a non-linear trend, in other words a change in the trend observed, the trend component $\beta$ should be considered,

- The coefficient $\beta$ can be determined in proportional to the trend changes rate in the real,

- If there are more or less repeated changes at regular intervals in the series, seasonality component $\delta$ should be considered,

- Some waveforms in the time series move by sliding in the periods and this situation should be kept out of the seasonality. Otherwise the error rate can increase depending on the width of the slide,

\section{For adaptive smoothing;}

- If major and permanent changes (steps, shifts, unidirectional and quick rises etc.) reveals on the series in non-periodic intervals, adaptive smoothing method may be preferred,

- If the changes happen on the very short-term as unstable fluctuations, using classic adaptive smoothing method may not be a solution. Because the error rates may increase. However, improved adaptive smoothing methods can offer solutions to this problem because it contains certain constraints.

\section{ACKNOWLEDGMENT}

The study is selected from National Engineering Research Symposium 2015 (Ulusal Mühendislik Araştırmaları Sempozyumu) UMAS 2015 (Duzce University).

\section{REFERENCES}

[1] E.S. Gardner, "Exponential smoothing: the state of the art", Journal of Forecasting vol. 4, no. 1, pp. 1-28, 1985.

[2] E.S. Gardner, "Exponential smoothing: the state of the art-part II", International Journal of Forecasting, vol. 22, pp. 637-666, 2006.

[3] J.T. Mentzer, M.A. Moon, "Sales Forecasting Management: A Demand Management Approach", Sage Puplications, UK, 2005.

[4] J.S. William, "Operations Management", McGraw-Hill Higher Education,USA, 2012.

[5] J.W. Taylor, Smooth Transition Exponential Smoothing, Journal of Forecasting, vol. 23, pp. 385-404, 2004.

[6] J.T. Mentzer, "Forecasting with adaptive extended exponential smoothing", Journal of the Academy of Marketing Science, vol. 16, no. 34, pp. 62-70, 1988.

[7] R.J. Hyndman, A.B. Koehler, R.D. Snyder, G. Simone, "A state space framework for automatic forecasting using exponential smoothing methods", International Journal of Forecasting, vol. 18, no.3, pp. 439454, 2002.

[8] C.C. Pegels, "Exponential forecasting: some new variations", Management Science, vol. 12 pp. 311-315, 1969.

[9] D.W. Trigg, A.G. Leach, "Exponential smoothing with an adaptive response rate", Operational Research Quarterly, vol. 18, no. 1, pp. 5359, 1967.

[10] S. Ekern, "Adaptive exponential smoothing revisited", The Journal of the Operational Research Society, vol. 32, no. 9 pp. 775-782, 1981.

[11] S. Makridakis, A. Andersen, R. Carbone, R. Fildes, M. Hibon, R. Lewandowski, J. Newton, E. Parzen, R. Winkler, "The accuracy of extrapolation (time series) methods: Results of a forecasting competition", Journal of Forecasting, vol. 1, pp. 111-153, 1982.

[12] D.C. Whybark, "Comparison of adaptive forecasting techniques", Logistics Transportation Review, vol. 8, pp. 13-26, 1973.

[13] D.W. Bunn, "Adaptive forecasting using the Kalman filter", Omega, vol. 9, pp. 323-324, 1981.

[14] P.C. Young, "Nonstationary time series analysis and forecasting", Progress in Environmental Science, vol. 1, pp. 3-48, 1999.

[15] J.T. Mentzer, R. Gomes, "Further extensions of adaptive extended exponential smoothing and comparison with the M-Competition", Journal of the Academy of Marketing Science, vol. 22, pp. 372-382, 1994.

[16] S.N. Pantazopoulos, C.P. Pappis, "A new adaptive method for extrapolative forecasting algorithms", European Journal of Operational Research, vol. 94, pp. 106-111, 1996.

[17] C.W.J. Granger, T. Teräsvirta, "Modelling nonlinear economic relationships, advanced texts in econometrics", Oxford University Press: New York, 1993.

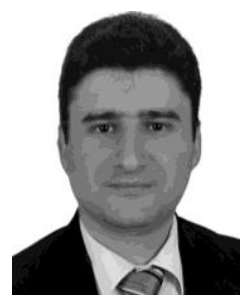

Yunus BICEN received the MSc. degree in Electrical Education from the University of Kocaeli in 2006 and the $\mathrm{PhD}$ degree in 2012 at the same university. He is presently working as Assist. Prof. at the Department of Electronics and Automation in the University of Duzce. His research interests are in power system condition monitoring, service lifetimes, transformers and cables.

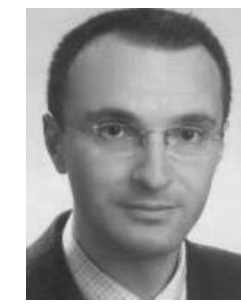

Mustafa KAYIKCI received the MSc. degree in Faculty of Arts and Sciences Mathematics from the University of Sakarya in 2003 and the $\mathrm{PhD}$ degree in 2010 at the same university. He is presently working as Assist. Prof. at the Department of Computer Technologies in the University of Duzce. His research interests are in double-dimensional arrays spaces, Riesz difference sequence spaces. 


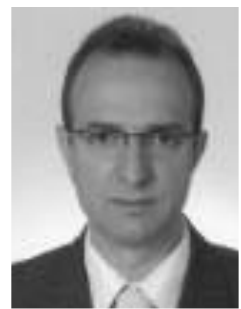

Faruk ARAS received the B.Sc. degree from Marmara University, Electrical Education Department, Istanbul, Turkey in 1994, the MSc and PhD degrees from Kocaeli University, Kocaeli, Turkey in 1996 and 2001, respectively. $\mathrm{He}$ is a Professor at the Department of Aircraft Electrical and Electronics in Kocaeli University. His current research interests are in the area of power system, aging, cables and transformers. 